
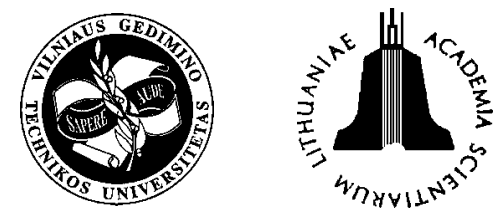

JOURNAL OF CIVIL ENGINEERING AND MANAGEMENT

http:/www.jcem.vgtu.lt

2004, Vol X, No 4, 261-266

\title{
HARDENED MATERIAL PROPERTIES OF SELF-COMPACTING CONCRETE
}

\author{
Klaus Holschemacher \\ Leipzig University of Applied Sciences (HTWK Leipzig), Dept of Civil Engineering. \\ Karl-Liebknecht-Strasse 132, D-04329 Leipzig, Germany.E-mail: holschem@fbb.htwk-leipzig.de
}

Received 24 Aug 2004; accepted 30 Nov 2004

\begin{abstract}
Self-compacting concrete (SCC) is an innovative construction material with a favourable rheological behaviour, which is caused by its modified concrete composition. Based on this fact SCC offers improved fresh concrete but also hardened material properties and therefore many advantages regarding the productivity and the design potential compared with normal vibrated concrete. Consequently, the amount of SCC, used for structural purposes has strongly increased worldwide in the last years. In this context it is necessary to know, if it is possible to apply the current design rules, eg Model Code 90 and Eurocode 2, that are based on years of experience on normal vibrated concrete, to structural members made of SCC as well. This paper represents the analysis of own and internationally published test results of the compressive strength, tensile strength, modulus of elasticity, bond behaviour and the time-dependent deformations of SCC in comparison with conventional concrete, in order to give a general statement regarding the agreements and differences between the hardened material properties of these concretes.
\end{abstract}

Keywords: self-compacting concrete, hardened concrete properties, tensile strength, modulus of elasticity, creep and shrinkage, bond behaviour.

\section{Introduction}

SCC, primarily invented in Japan in the late 1980's $[1,2]$, has developed more intensively only in the last decade. In this time the application of SCC has increased and many investigations all over the world were carried out to find optimal and economical mix compositions, which guarantee the typical fresh concrete behaviour of SCC. Meanwhile, there are various concepts for the production of SCC-mixes, which vary mainly in the amount and kind of used additives and admixtures [3-5].

Due to the optimised combination of its mix components SCC is capable to compact itself only under its own weight without the internal or external vibration energy and deaerates itself almost completely while flowing in the formwork. Furthermore, SCC is able to fill all recesses and reinforcement spaces, even in high reinforced concrete members and flows free of segregation near to level balance. These specific material properties were achieved by the excellent coordination of deformability and segregation resistance.

Based on these properties, SCC may contribute to a significant improvement of the quality of concrete structures and open up new fields for the application of concrete [6].

The designation "self-compacting" is based on the fresh concrete properties of this material and therefore the degree of compactability, the deformability and the viscosity in connection with different mix compositions were investigated very frequently. However, it is also to verify, to what extent the modifications of the mix composition of SCC have an effect on the hardened concrete properties as well as the durability. This fact formed the basis of the creation of a database with currently known data of own and internationally published test results of hardened concrete properties of SCC. Thus the database represents the first step in the analysis and generalisation of the numerous investigations of individual researchers.

\section{Scope of the investigation}

\subsection{Initial situation}

A good starting point to discuss the hardened material properties of self-compacting concrete is the mix composition of this material.

Independent of the fact that SCC consists basically of the same components as normal vibrated concrete, there exist clear differences regarding the concrete composition in order to achieve the desired "self-compacting properties". On the one hand, SCC has to reach a high segregation resistance and, on the other hand, a high deformability. Therefore the content of ultrafine materials at SCC is essentially higher. For this purpose various fillers, eg limestone powder, fly ash, blast furnace slag, quartzite powder and silica fume, are given to the mixture or the content of cement will be increased. Furthermore, a larger quantity of superplasticiser has to be added 
and stabiliser is used, if required. Fig 1 shows a typical mix composition of SCC compared with normal vibrated concrete in principle [7,8].

On the basis of the stated differences between the mix composition of SCC and conventional concrete it is necessary to analyse the effects of these modifications on the hardened concrete properties. So, referring to this, the applicability of the currently existing design rules based on years of experience on normal vibrated concrete has to be examined carefully.

Reasons for possible differences between the hardened properties of SCC and conventional concrete may be the modified mix composition as mentioned before, the better microstructure and homogeneity of SCC and the absence of vibration.

The higher content of ultrafine materials and the accordingly lower content of coarse aggregates change the granular skeleton. This could influence the strength as well as the modulus of elasticity, since the modulus of elasticity of the several components defines that one of the concrete. Moreover, the addition of fillers leads to a different reaction with water and therefore in connection with the use of superplasticiser the water demand changes. Due to the increased content of ultrafines (cement, filler) in SCC the grain-size distribution and packing density will be improved and therefore the bulk of the cement paste is stable, coherent and flowable and the porosity of the interfacial transition zone (ITZ) between aggregate and cement paste is decreased. Consequently, the tensile strength of SCC could be increased compared with conventional concrete, because of the fact that the transfer of tensile loads is supplied by the adhesion of the cement matrix or the bond within the ITZ, by friction and by aggregate interlock between the crack flanks.

Caused by the absence of vibration, gross defects by vibration cannot arise but on the other hand the selfdeaeration while flowing in the formwork has to be realised surely in order to avoid new sources of error.

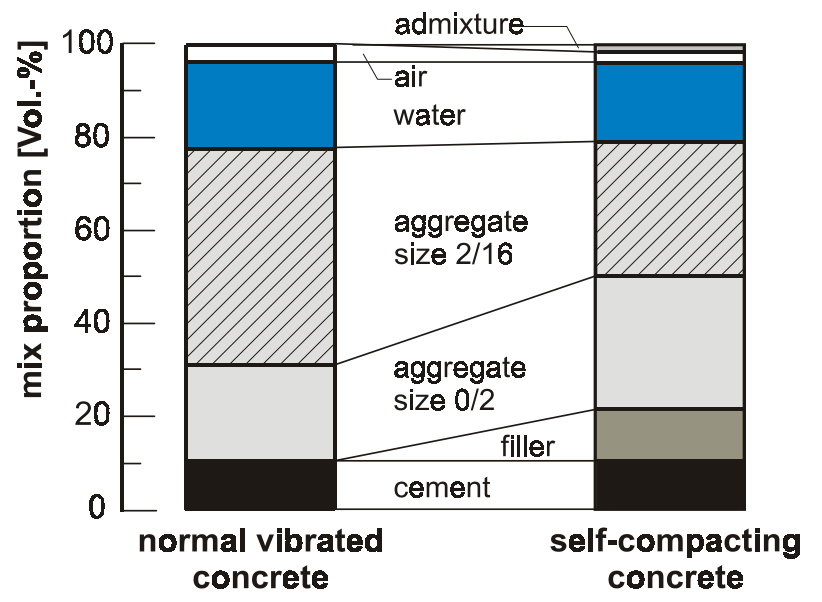

Fig 1. Comparison of typical mix compositions of SCC and normal vibrated concrete

\subsection{Aim of the investigation}

The aim of the performed investigations was to compare the hardened material properties of SCC with those of normal vibrated concrete, ultimately to give a general estimation regarding the application of the current design codes or calculation methods respectively in case of the usage of SCC.

Thereupon a database with results of own experimental investigations and a large number of internationally published data of design relevant to hardened material properties of several self-compacting concretes was created [9-11]. The data of properties such as compressive strength, tensile strength, modulus of elasticity, bond strength and the time-dependent deformations were documented and analysed particularly with regard to the given values and limits of the European design code "CEBFIB Model Code" [12]. This strategy seemed to be expedient because the [12] is the basis of the future uniform European rules, the Eurocode 2 [13]. A total overview of the test reports that were used for the creation of the data base is given in [9].

Reports regarding the hardening properties of SCC are quite frequently in literature, for example $[6,14,15]$. However, the import of the published test results into a database is frequently problematic owing to the following facts:

- there are often insufficient statements concerning the exact mix compositions, curing conditions and dimensions of used specimens;

- there exists a wide spectrum of different mix compositions;

- the initial parameters of diverse investigations differ strongly from each other.

Nevertheless, by the interpretation of the created database it is possible to recognise the basic relations and dependencies of the hardened properties of self-compacting concrete and to compare them with the wellknown rules, valid for normal concrete. For this purpose all utilised data of considered concrete properties are represented in diagrams.

Based on the realities mentioned above, the following sections try to demonstrate the present level of knowledge regarding the most important design-relevant hardened concrete characteristics of SCC.

\section{Parameter study of the hardened material proper- ties of SCC}

\subsection{Compressive strength}

In general, in national and international codes concrete is classified on the basis of its compressive strength, because compressive strength is the most important mechanical property of concrete for the most applications. Since the compressive strength depends on the mechanical properties of the hardened cement paste and the adhesion within the ITZ, it is of interest whether the 
differences in the concrete composition and the positive changes in the microstructure, as mentioned before, have an effect on the short and long term load-bearing behaviour. Moreover, clarification is still necessary to determine whether the hardening process and the ultimate strengths of SCC and conventional concrete differ.

Corresponding to the characteristic compressive strength $f_{c k}$ of cylinders and cubes, concrete is classified in concrete grades. As is known, there exists a certain dependence on the specimen geometry with conventional concrete [9]:

$$
\frac{f_{\mathrm{c}, \mathrm{cyl}(150 / 300)}}{f_{\mathrm{c}, \text { cube }(150)}}=0,8 \ldots 0,85 \text {. }
$$

However, my own tests carried out in Leipzig have shown that this well-known relation between cylinders and cubes could not be confirmed with SCC in the expected magnitude. A clearly lower dependency was ascertained:

$$
\frac{f_{\mathrm{c}, \mathrm{cyl}(150 / 300)}}{f_{\mathrm{c}, \text { cube }(150)}}=0,9 \ldots 1,00 .
$$

Mostly the compressive strength of SCC and normal vibrated concrete at the age of 28 days of similar composition does not differ drastically, but in a few cases higher values were observed for SCC. Compared with the majority of the published test results, the tendency becomes obvious that at the same water-cement ratios higher compressive strengths were reached for SCC. This fact gets along with the decreasing water-binder-ratio corresponding to the rising amount of fillers. However, an explicit research programme regarding this topic does not exist so far and therefore a generalised conclusion cannot be drawn.

The strength development of SCC is subjected to similar dependencies like conventional concrete in general (Fig 2). Some of the published test results show that an increase of the cement content and a reduction of filler content at the same time cause an increase in concrete strength. For young SCC (aged up to 7 days) the relative compressive strength spreads to a greater extent as given in the Model Code 90, whereas higher values as well as lower values are reached. Especially when limestone powder is used, higher compressive strengths are noticeable at the beginning of the hardening process. At higher concrete ages SCC often exceeds the valid range according to the given limits by Model Code 90 . Using fly ash or silica fume this will be caused by the pozzolanic effect of these fillers.

\subsection{Tensile strength}

All parameters, which influence the characteristics of the microstructure of the cement matrix and of the ITZ, are of decisive importance in regard to the tensile load bearing behaviour. Fig 3 shows the arranged data of the splitting tensile strength of several self-compacting concretes.

By evaluating the created database it can be shown, that the most of the measured values are within the valid range of current regulations for normal vibrated concrete. However, in about $30 \%$ of all data points clearly higher splitting tensile strengths were reached. Therefore, the tendency of higher tensile strengths of self-compacting concretes becomes obvious, especially if fly ash and silica fume is applied.

Presumably the reason for this fact is given by the better microstructure again, especially due to the lower and more evenly distributed porosity within the interfacial transition zone with SCC, which is caused by the higher content of ultrafines. Further on, the denser cement matrix of SCC enables a better load transfer.

The time development of the tensile strength of SCC and normal vibrated concrete is subject to a similar dependence. Only few publications about SCC refer to a more rapid increase of the tensile strength in comparison to compressive strength [14].

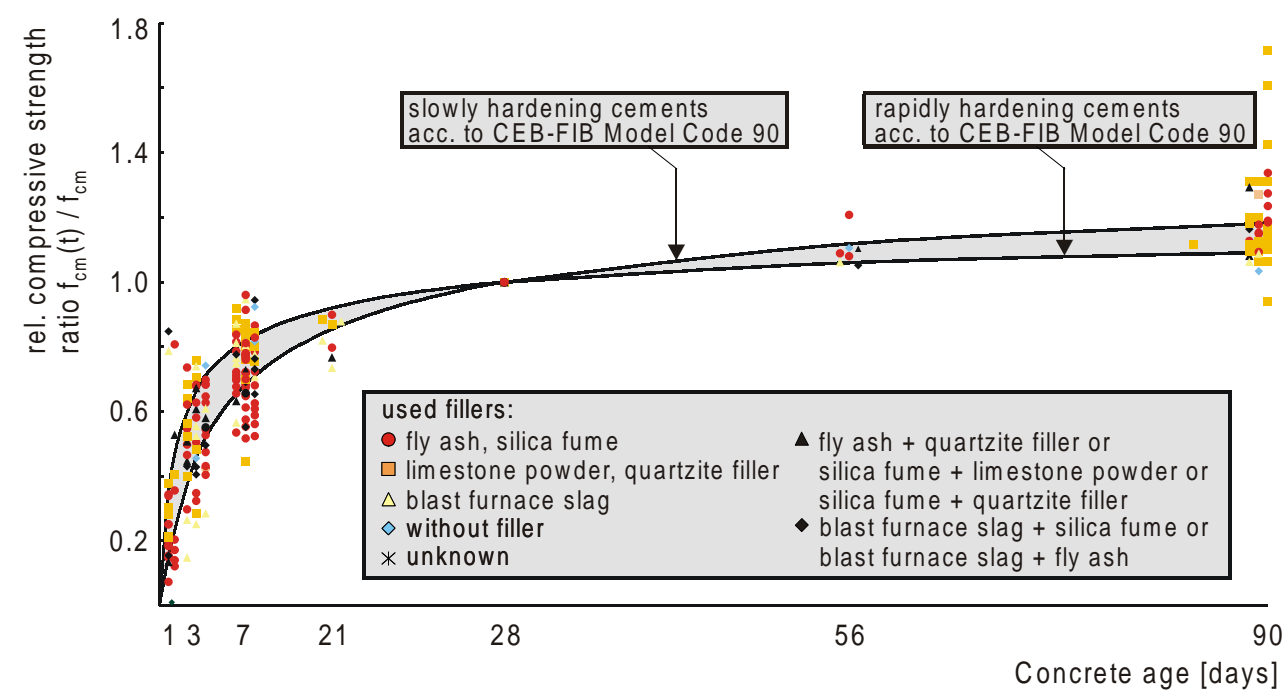

Fig 2. Development of compressive strength of SCC with time in comparison with the regulations of Model Code 90 [12] 


\subsection{Modulus of elasticity}

As it is known, the modulus of elasticity of concrete depends on the proportion of the Young's modules of the individual components and their percentage by volume. Thus, the modulus of elasticity of concrete increases with higher contents of aggregates of high rigidity, whereas it decreases with increasing hardened cement paste content and increasing porosity. For this reason lower values of modulus of elasticity can be expected, because of the higher content of ultrafines and additives as dominating factors and the accordingly lower content of coarse, stiff aggregates with SCC. The evaluation of the data really shows the fact that the modulus of elasticity of SCC is within the lower half of the scattering range according to the Model Code 90. More exactly, the average value valid for conventional concrete represents the upper limit for SCC, whereas all values were always referred to the mean compressive strength (Fig 4).

\subsection{Time-dependent deformations}

Shrinkage and creep are very complex processes regarding the restructuring several components of the concrete structure caused by changes in the humidity balance. Furthermore, these time-dependent investigations require time and high technological expenditure. Due to this fact only few data of the plastic shrinkage and the autogenous shrinkage of SCC as well as the time-dependent deformation behaviour under load are published in literature and very different conclusions about these material properties are stated. The drying shrinkage of SCC, however, is examined several times.

A general agreement exists on the fact that SCC is influenced in the same way by the water-cement ratio and the curing method as normal vibrated concrete. The modified aggregate combination, especially the relation of coarse and fine aggregates as well as fineness (Blaine) and content of ultrafines seems to influence the shrinkage deformations. Thus such deformations of SCC can increase due to a lower content of coarse aggregate and the minimum paste volume, which must be present for ensuring the optimal self-compaction of SCC without segregation. As a result, the conclusion could be drawn that the shrinkage deformations of SCC can achieve clearly higher values than the ones of comparable normal vibrated concretes. However, a denser microstructure of the cement paste can be achieved by addition of fillers with a fineness larger than that of cement, whereby the shrinkage can be affected positively. So, it is possible to modify the SCC mix in such a way that smaller shrinkage deformations appear, similar to those of normal vibrated concrete.

Fig 5 shows the relationship between shrinkage and concrete age. The identified areas mark the limits for shrinkage deformations of $\mathrm{C} 20$ up to $\mathrm{C} 80$ with a relative humidity of $60 \%$ and notional member size of 50 according to the Model Code 90, since all considered self-compacting concretes of the database meet these conditions.

In the majority of the evaluated data the shrinkage of SCC is 10 to $50 \%$ higher than the one of conventional concrete. Remarkable is the substantially steeper rise of the deformations, particularly for young concrete aged up to 28 days.

With rising age the deformations approach to the limit values of the current standard. Partly similar and in some cases smaller deformations were observed, especially when limestone powder was used in the concrete mix. The early age shrinkage of SCC is substantially stronger pronounced in contrast to conventional concrete, which can be related to the increased flour grain portion.

\subsection{Other aspects}

Due to the fact that the bond behaviour is strongly affected by the reinforcement properties on the one hand

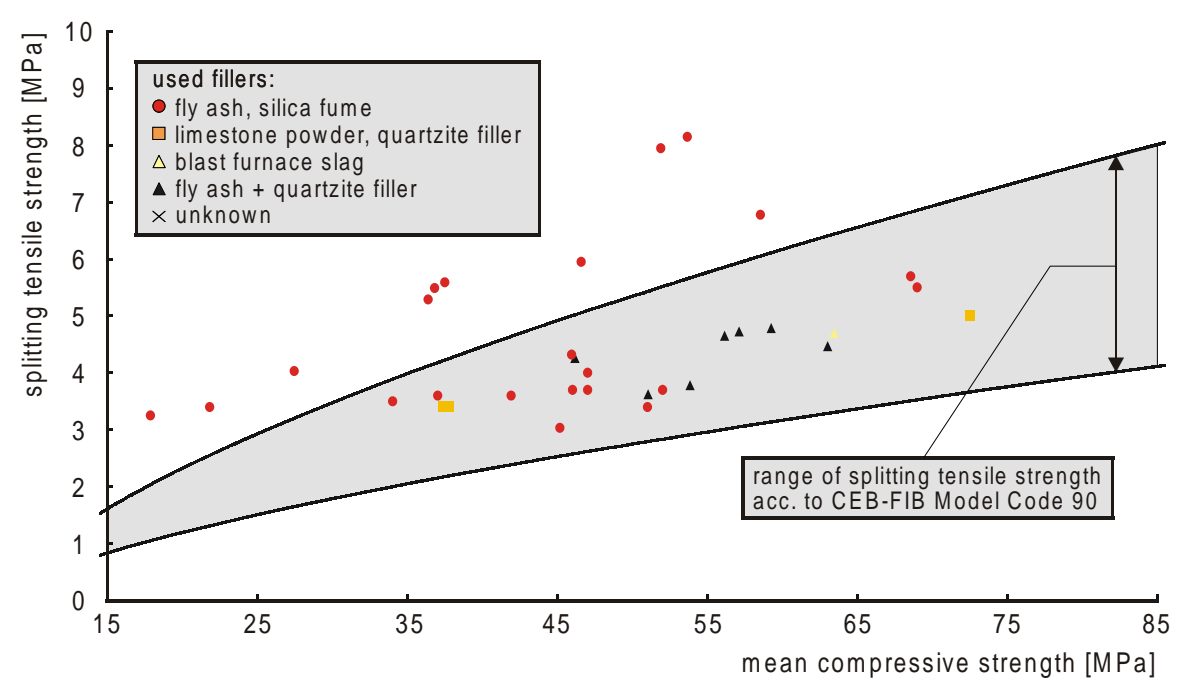

Fig 3. Data base of the splitting strength of SCC with reference to the corresponding compressive strength in comparison with the regulations of Model Code 90 [12] 


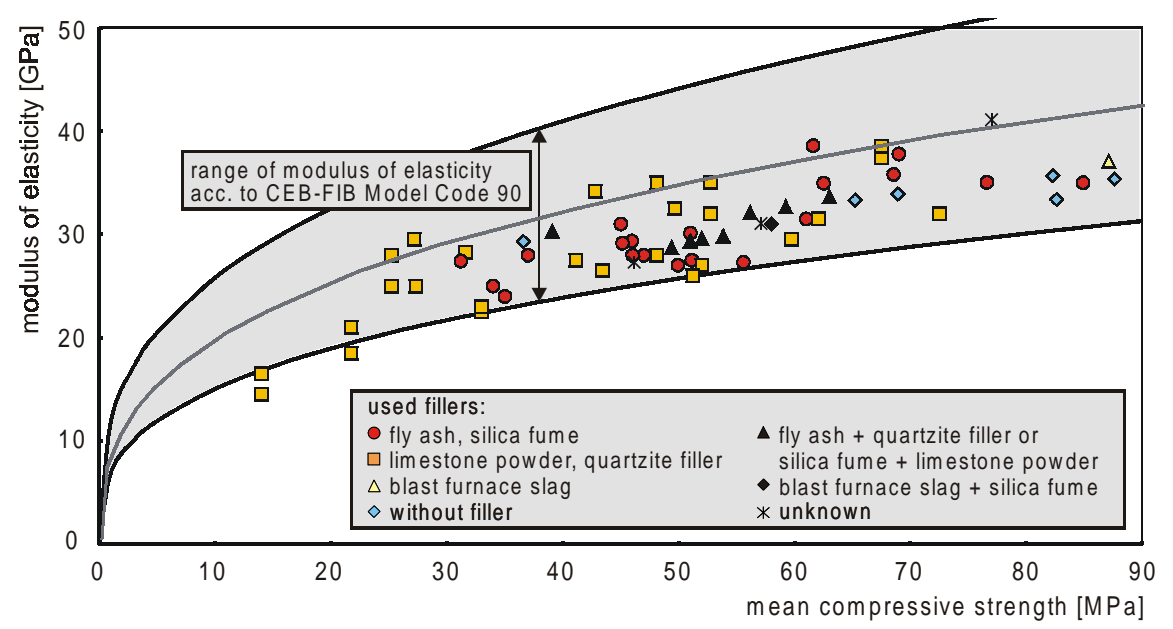

Fig 4. Data base of the modulus of elasticity of SCC with reference to the corresponding compressive strength in comparison with the regulations of Model Code 90 [12]

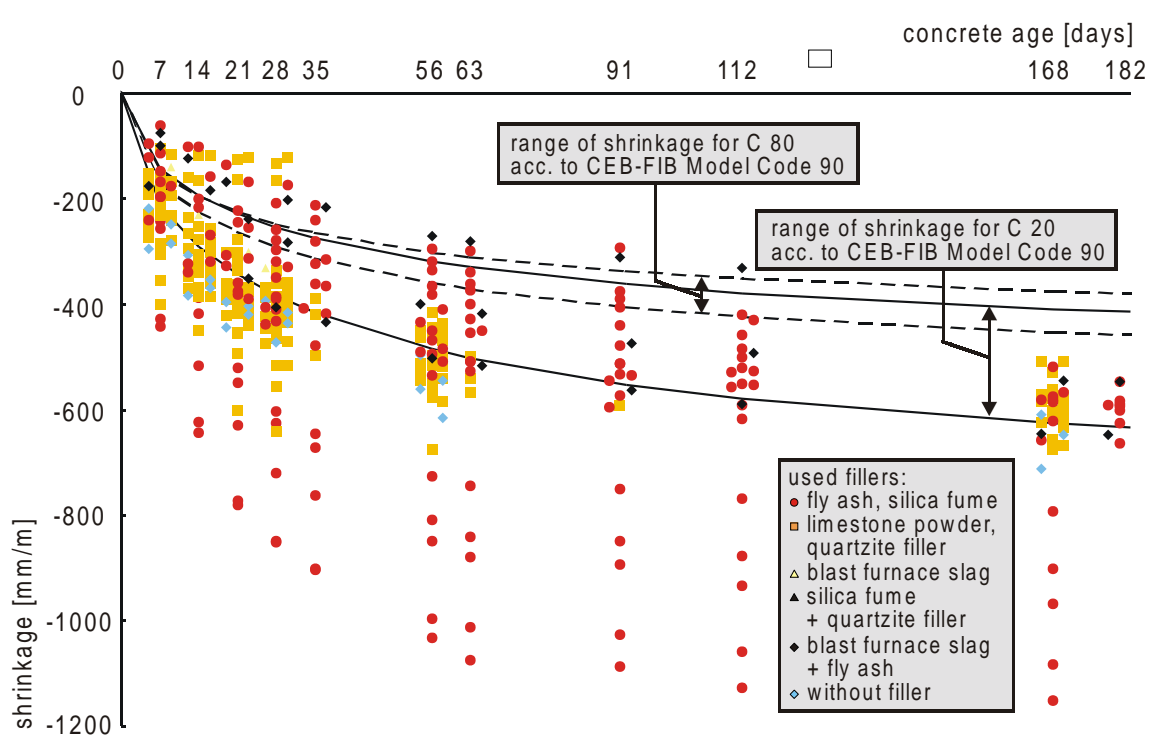

Fig 5. Data base of the shrinking deformations of SCC at different concrete ages in comparison with the regulations of Model Code 90 [12]

and the surrounding matrix on the other hand the bond behaviour of SCC is different from that one of conventional concrete. In our own tests an improvement of the bond stiffness in the serviceability limit state and a very ductile bond behaviour after reaching the maximum load was ascertained for SCC [16-20]. However, the maximum bond strength of SCC is lower than that of a normal vibrated concrete of comparable strength.

A positive effect of the high segregation resistance of SCC is the better homogeneity. Hence, the concrete strength could be more evenly distributed referring to the overall member. Indeed, in some investigations it was found that the concrete strength measured at different locations of a construction member spreads less than in members of conventional concrete [21].

\section{Conclusions}

The described investigations show that an exact identity between the mechanical properties of SCC and normal vibrated concrete does not exist. The results of the interpretation of the data base can be summarised as follows:

- The concrete strength of SCC and conventional concrete is similar under comparable conditions, whereas the tendency is obvious that SCC shows higher strengths with same water-cement ratios. The definite relation, however, is still to be clarified.

- The development of concrete strength with time is similar. Deviations are to be recognised depending on the type of filler.

- The dependence of the compressive strength on the specimen geometry of SCC is only inarticulately pronounced compared with the well-known relation of conventional concrete. However, this fact is subject to review.

- The splitting tensile strength achieves clearly higher values, partly up to $40 \%$ higher than in the current standard. Thus, there is a need for action regarding the minimum amount of reinforcement. The modulus of elasticity of SCC is slightly lower 
but within the upper half of the standardised limits.

- The shrinking deformations of SCC are up to $50 \%$ higher, especially at concretes aged up to 28 days. Regarding the creep deformations there are only insufficient test results known, thus it is necessary to carry out further investigations.

- The bond behaviour of reinforcement in SCC is partly better than in comparable vibrated concrete.

Based on these facts, it can be concluded that extra design rules for SCC may not be necessary. However, it seems to be useful to add regulations regarding the minimum reinforcement and the time-dependent deformations to the current standards.

In this regard further research projects are required to interpret the dependencies of the hardened material properties of SCC more precisely. Referring to this the influence of any parameter, eg type of cement and filler as well as their portion, water-binder/ -cement ratio, proportion of fine and coarse aggregates and fineness have to be investigated specifically.

To benefit from the advantages of SCC not only the fresh concrete properties but also the design relevant hardened material properties have to be known accurately. Only in this way SCC can be used conveniently and a realistic calculation of structural members made of this innovative material is possible.

\section{References}

1. Okamura, H. Expectation to the New Concreting Material. Cement and Concrete Journal, No 475. Cement Association of Japan, 1986 (in Japanese).

2. Okamura, H. and Ozawa, K. Mix Design for Self Compacting Concrete. Concrete Library International, No 25. Japan Society of Civil Engineers, June 1995, p. 107-120.

3. Skarendahl, A. The Presnt - the Future. In: Proceedings of the 3rd International RILEM Symposium on Self-Compacting Concrete. Reykjavik, Iceland, 17-20 Aug 2003. Ed by O. Wallevik and I. Nielsson, RILEM Publication s.a.r.1, Bagneux, France, 2003, p. 6-14.

4. Walraven, J. Structural Aspects of Self-Compacting Concrete. In: Proceedings of the 3rd International RILEM Symposium on Self-Compacting Concrete. Reykjavik, Iceland, 17-20 Aug 2003. Ed by O. Wallevik and I. Nielsson, RILEM Publication, Bagneux, France, 2003, p. 15-22.

5. Wallevik, O. Rheologa - a Scientific Approach to Develop Self-Compacting Concrete. In: Proceedings of the 3rd International RILEM Symposium on Self-Compacting Concrete. Reykjavik, Iceland, 17-20 Aug 2003. Ed by O. Wallevik and I. Nielsson, RILEM Publication, Bagneux, France, 2003, p. 23-31.

6. Skarendahl, A. and Petersson, Ö (eds). Proceedings of the 1st International RILEM Symposium on Self-Compacting Concrete. Stockholm, Sweden, Sept 13-14, 1999. Cachan, France: RILEM Publications, 1999. 786 p.

7. Holschemacher, K. and Weiße, D. Self-Compacting Concrete in Practice. Concrete Plant International, No 1, 2002, p. 74-81.

8. Holschemacher, K. and Weiße, D. Structural Aspects of Self-Compacting Concrete. New Building Materials and Construction World, July 2002, p. 8-12.
9. Holschemacher, K. and Klug, Y. A Data Base for the Evaluation of Hardened Properties of SCC. In: Leipzig Annual Civil Engineering Report No 7. University of Leipzig, Leipzig, 2002, p. 123-134.

10. Klug, Y. and Holschemacher, K. Material Properties of Hardened Self-Compacting Concrete. In: Proceedings of the International Conference on Performance of Construction Materials in the New Millennium - a New Era of Building, Cairo, Egypt, 18-20 Feb 2003. Ed by A. S. ElDieb, M. M. Reda Taha and S. L. Lissel, Elmaarefa Printing House, 2003.

11. Klug, Y. and Holschemacher, K. Comparison of the Hardened Properties of Self-Compacting and Normal Vibrated Concrete. In: Proceedings of the $3^{\text {rd }}$ International RILEM Symposium on Self-Compacting Concrete. Reykjavik, Iceland, 17-20 Aug 2003. Ed by O. Wallevik and I. Nielsson, RILEM Publication, Bagneux, France, 2003.

12. CEB-FIB Model Code 1990. Design Code. Lausanne, Switzerland: Thomas Telford Services Ltd, 1991. 637 p.

13. Eurocode 2: Design of Concrete Structures. Draft July 2002.

14. RILEM Publications Pro 7: Proceedings of the 1st RILEM International Symposium, Stockholm, Sweden, 13-14 Sept, 1999. Ed by Å. Skarendahl and Ö. Petersson, RILEM Publications, France, 1999. 804 p.

15. RILEM Publications Pro 33: Self-Compacting Concrete. Proceedings of the 3rd International RILEM Symposium, Reykjavik, Iceland, 17-20 Aug, 2003, Ed by O. Wallevik and I. Nielsson, RILEM Publications, Bagneux, France, 2003. $1048 \mathrm{p}$.

16. Holschemacher, K.; Klug, Y.; Weiße, D.; König, G. and Dehn, F. Bond Behaviour of Reinforcement in Self-Compacting Concrete (SCC). In: Proceedings of the 2nd International Structural Engineering and Construction Conference (ISEC02), Roma, Italy, 23-26 Sept 2003.

17. König, G.; Holschemacher, K.; Dehn, F. and Weiße, D. Bond of Reinforcement in Self-Compacting Concrete under Monotonic and Cyclic Loading. In: Proceedings of the 3rd International RILEM Symposium on Self-Compacting Concrete. Reykjavik, Iceland, 17-20 Aug 2003. Ed by O. Wallevik and I. Nielsson, RILEM Publication, Bagneux, France, 2003, p. 15-22.

18. König, G.; Holschemacher, K.; Dehn, F. and Weiße, D. Self-Compacting Concrete - Time Development of Material Properties and Bond Behaviour. In: Proceedings of the 2nd International Symposium on Self-Compacting Concrete, Tokyo. Oct, 23-25, 2001, p. 507-516.

19. König, G.; Holschemacher, K.; Dehn, F. and Weiße, D. Determination of the Bond Creep Coefficient for Self-Compacting Concrete. In: Proceedings of the $3^{\text {rd }}$ International Symposium on Bond in Concrete - From Research to Standards. Budapest, Hungary, Nov. 20-22, 2002. Ed by G. L. Balasz, P. J. M. Bartos, J. Cairns and A. Borosnyoi, 2002.

20. Holschemacher, K. and Weiße, D. Self-Compacting Concrete Made with Sand-Rich Particle Fractions. In: IABSE Symposium Towards a Better Built Environment - Innovation, Sustainability, Information Technology, Melbourne, Australia, 8-13 Sept, 2002.

21. Khayat, K. H.; Manai, K. and Trudel, A. In Situ Mechanical Properties of Wall Elements Cast Using Self-Consolidating Concrete. ACI Materials Journal, Vol 96, Issue 6, 1997, p. 491-500. 